\title{
Application of electrospray ionization mass spectrometry fingerprinting associated with macroscopic and histological analysis for Plantago major herbal infusions quality control ${ }^{\text {is }}$
}

\author{
Carolina Gomes de Andrade ${ }^{\mathrm{a}}$, Leonardo Mendes de Souza Mesquita ${ }^{\mathrm{a}, \mathrm{b}}$, Daniella Carisa Murador ${ }^{\mathrm{b}}$, \\ Anna Rafaela Cavalcante Braga ${ }^{\mathrm{b}, \mathrm{c}}$, Veridiana Vera de Rosso ${ }^{\mathrm{b}, *}$, Odair José Garcia de Almeida ${ }^{\mathrm{a}}$, \\ Wagner Vilegas ${ }^{\mathrm{a}}$ \\ ${ }^{a}$ UNESP - São Paulo State University/Coastal Campus of São Vicente, Laboratory of Bioprospection of Natural Products (LBPN), Pça Infante Dom Henrique S/N, 11330- \\ 900 São Vicente, SP, Brazil \\ ${ }^{\mathbf{b}}$ Department of Biosciences, Federal University of São Paulo (UNIFESP), Silva Jardim Street, 136, Vila Mathias, 11015-020 Santos, SP, Brazil \\ ${ }^{\mathrm{c}}$ Department of Exact and Earth Sciences, Federal University of São Paulo (UNIFESP), Campus Diadema, 09972-270 Diadema, SP, Brazil
}

\section{A R T I C L E I N F O}

\section{Keywords:}

Leafy herbal teas

Aflatoxins

Microscopic control

Mass spectrometry

Antioxidant activity

Plantago

\begin{abstract}
A B S T R A C T
The present study demonstrates the need to conduct an integrative quality control of teas marketed as Plantago major. In the present study, quality control checks were performed through macroscopic, microscopic and chemical analyses of commercial brands. Leaves with parts not allowed for consumption were found in all brands. Six brands showed histological similarity $<50 \%$ with the authentic $P$. major. Eight brands demonstrated low chemical similarity (40 to 60\%), indicating that they do not have the same compounds from the authentic $P$. major. All commercial samples are contaminated with aflatoxins, indicative of fungicide contamination and consequent degradation of phenolic compounds and reduction of antioxidant activity from the commercial samples. The difference in the present study is the integrative application of methods for success in the quality control of $P$. major, which can be applied to other species. Thus, more rigorous inspection actions in the production of teas to guarantee the therapeutic benefit of these products.
\end{abstract}

\section{Introduction}

Natural products are used worldwide to treat a variety of diseases in humans and animalsare among the best resources for the discovery of new therapeutic products ( $\mathrm{Ji}, \mathrm{Li}$, \& Zhang, 2009). Leafy herbal teas contain a variety of active phytochemicals with biological properties that promote human health and help reduce the risk of chronic diseases such as allergies, insomnia, headaches, anxiety, intestinal disorders, and high blood pressure (Oh, Jo, Cho, Kim, \& Han, 2013). Although consumer acceptance of these products is high, there is great concern expressed by regulatory agencies that the current quality control and standardization procedures for botanical products are not sufficient to ensure their effectiveness and safety (Govindaraghavan \& Sucher, 2015). Therefore, due to the importance of medicinal plants, the (World Health Organization, 2014) has emphasized the necessity to ensure the quality of medicinal plant products by using modern controlled technique, i.e., fingerprinting and application of suitable standards (Pandey,
Shukla, Saraf, \& Saraf, 2013).

Plantago major L., a perennial plant belonging to the Plantaginaceae family, is a medicinal plant used in many parts of the world for the treatment of several diseases, such as skin conditions, infectious diseases and gastrointestinal problems (Samuelsen, 2000). Plantago L. species are consumed as fresh salads or soups, or they can be used as herbal tea (Beara et al., 2012). Plantago major, wich is rich in carbohydrates, lipids, caffeic acid and derivatives, flavonoids, terpenes, $\beta$ carotene and ascorbic acid, can be used as a food supplement, since it is high in fiber and vitamins (Samuelsen, 2000).

Flavonoids, phenylethanoides glycosylated and iridoids are a group of polyphenolic compounds present in Plantago species, with known properties including free radical scavenging, inhibition of hydrolytic and oxidative enzymes and anti-inflammatory action (Janković et al., 2012; Rønsted, Göbel, Franzyk, Jensen, \& Olsen, 2000). These substances show antibacterial, cytotoxic and immunomodulatory hepatoprotective activities and are considered responsible for the medicinal

\footnotetext{
The authors have declared that there was no conflict of interest.

* Corresponding author.

E-mail address: veridiana.rosso@unifesp.br (V.V. de Rosso).
} 
use of the genus (Qi, Xiong, Geng, Li, \& Wang, 2012). Iridoids and phenylethanoides have excellent antioxidant activity and are the most representative secondary metabolites of Plantago genus and are suitable markers for chemotaxonomic studies (Rønsted et al., 2000).

Due to the centuries old importance of this plant, the correct botanical and chemical identification of the Plantago herbs is necessary, since its commercialization for the preparation of infusions is a worldwide reality. The anatomical analysis will reveal important features useful to demonstrate the quality of the herbal teas. Recently, (de Souza Mesquita et al., 2017) studied four close Plantago species used indiscriminately as Plantago major. Surprisingly, the authors found that even among species that showed few anatomic differences, these herbs are notably different with respect to the chemical compounds; therefore, they must not be used for the same medical purposes.

The present study aimed to perform a quality control for 10 different brands of Plantain (P. major) teas commercially available in drug stores from Brazil. We compared the results of electrospray ionization mass spectrometry fingerprinting and macroscopic and histological analyses of the commercialized samples to those of the control groups consisting of authentic Plantago species.

\section{Materials and methods}

\subsection{Samples}

Plantago major herbs, commercially available in pharmacies in Brazil, were acquired for the present study in the local market. Ten different brands were analyzed in triplicate ( 3 samples per brand), totaling 30 samples (packages). Authentic samples free from impurities (positive control) were collected at the Juréia-Itatins Ecological Station (city of Peruibe - SP - Brazil - 24 $26^{\prime} 19.07^{\prime \prime}$ S, $47^{\circ} 04^{\prime} 12.41^{\prime \prime}$ ), also in triplicate. Vouchers were deposited and registered at the Herbarium ESA at São Paulo University/USP, under the access number ESA 119208. The control was divided in two groups (i) with inflorescence (IC) and (ii) without inflorescence (NIC), the chemical composition of the plants can undergo changes depending on the stage of life, i.e., vegetative or reproductive (Poethig, 2013).

\subsection{Macroscopic control}

Macroscopic control was performed with the naked eye. All samples were analyzed individually. The contents were dumped on a tray and the inappropriate parts, such as bugs, stones, sediment, roots, barks, inflorescences and other debris, were qualified. Brazilian law (BRASIL, 2010) requires that only leaves from $P$. major can be marketed.

\subsection{Histological analysis}

The material for histological purposes were obtained in triplicate; that is, for each commercial brand were taken 3 aleatory sub-samples of $10 \%$ of the total weight of the package, and then it was mixed and considered a composite sample of each brand for further analysis. The material was conserved in ethanol $70 \%$ (Jensen, 1962) at $4{ }^{\circ} \mathrm{C}$. The rehydration of the leaf fragments collected from the packetswas based on the technique described in (Smith \& Smith, 1942). As the material was stored in ethanol $70 \%$, the samples was rehydrated to pure water through an inverse ethanol series (ETOH 50\%, ETOH 30\%, ETOH 10\% $1 \mathrm{~h}$ each step) followed by destilled water $\left(\mathrm{DH}_{2} \mathrm{O}\right)$. Subsequently, the material was boiled in $\mathrm{DH}_{2} \mathrm{O}$ for 5 min (3 times) and treated overnight in a solution of $2 \%$ potassium hydroxide $(\mathrm{KOH})$ for the recovering of the material shape. After reconstruction, the material was dehydrated in an ethanol series (Jensen, 1962) and embedded in methacrylate (Historesin, Leica) according to the manufacturer's instructions. In the samples were sectioned at $8 \mu \mathrm{m}$ on a rotary microtome and stained with toluidine blue $\mathrm{O}$ (dissolved in phosphate buffer - $\mathrm{pH}$ 7.2). The photographs were taken using a light microscope Suite Motic, equipped with image capture system. The plates were edited through Adobe Photoshop software.

For anatomical comparison, we used the information from species of Plantago major according to (de Souza Mesquita et al., 2017). The following minimum criteria for the microscopic identification of the Plantago major were considered: epidermal cells with irregular size and rounded in the abaxial and adaxial epidermis; amphistomatic, with small chambers; glandular trichomes on both surfaces; and a concaveconvex central rib, with presence of main bicolateral vascular bundle and heterogeneous mesophyll with 2-3 layers of palisade parenchyma and 5-6 layers of lacunar parenchyma.

\subsection{Phytochemical analysis}

\subsubsection{Chemicals}

Gallic acid (GA) and ABTS were purchased from Sigma-Aldrich (Saint Louis, MO, USA). Sodium carbonate and Folin-Ciocalteu's phenol reagent were provided by Applichem, GmbH, Darmstadt, Germany. All other solvents, such as $\mathrm{MeOH}$, water and reagents used in the mass spectrometry assays analysis were LC-MS grade.

\subsubsection{Herbal infusions preparation}

All 30 samples purchased and the positive control infusions were prepared in water. Infusions were made under the same conditions as those generally used in folk medicine. Boiling water $(100 \mathrm{~mL})$ was added to $5 \mathrm{~g}$ of vegetal material in an Erlenmeyer flask. The infusion was allowed to stand for $10 \mathrm{~min}$. Next, the solution was filtered through cotton wool, rotoevaporated and freeze-dried, lyophilized, and stored at $-40^{\circ} \mathrm{C}$.

\subsubsection{Electrospray ionization mass spectrometry fingerprinting}

Flow injection analysis (FIA) was performed using a Thermo Finnigan Fisher (San Jose, CA, USA) mass spectrometer equipped with an electro-spray ionization source, ion-trap analyzer and Xcalibur software for data processing (ESI-MS/MS) LTQXL All lyophilized infusions were diluted and homogenized in $\mathrm{MeOH}: \mathrm{H}_{2} \mathrm{O}(8: 2 \mathrm{v} / \mathrm{v})$ at $5 \mathrm{ppm}$. The mass spectrometry analysis was performed according to (de Souza Mesquita et al., 2017)). The MS and MS $^{\mathrm{n}}$ analysis in negative ion mode were selected at a flow rate of $5 \mu \mathrm{L} \cdot \mathrm{min}^{-1}$ and working under the following conditions: capillary voltage $-31 \mathrm{~V}$, spray voltage $5 \mathrm{kV}$, tube lens offset $75 \mathrm{~V}$, capillary temperature $300{ }^{\circ} \mathrm{C}$, and a sheath gas $\left(\mathrm{N}_{2}\right)$ flow rate 8 (arbitrary units). Mass spectra were recorded in the range $m / z$ 100-2000 Da. The first event was a full scan mass spectrum to acquire data on ions in the $m / z$ range. The second scan event was an $\mathrm{MS}^{\mathrm{n}}$ experiment performed using a data-dependent scan performed on deprotonated molecules from the compounds at collision energy of $20 \%-30 \%$ and activation time of $30 \mathrm{~ms}$.

\subsubsection{Total phenolic contents}

All lyophilized infusions, including control groups, were diluted in distilled water to a known concentration $(\mathrm{mg} / \mathrm{mL})$. The determination of total phenolic was performed using Folin-Ciocalteu reagent according to (Singleton \& Rossi, 1965). A standard curve of gallic acid was used, and the results were expressed in mg Gallic Acid Equivalent (GAE)/g tea.

\subsubsection{Antioxidant capacity by ABTS radical cation decolorization}

Hydrophilic extracts were prepared diluting the lyophilized infusion, including control groups, with $80 \%$ acetone at known concentrations $(\mathrm{mg} / \mathrm{mL})$. ABTS and potassium persulfate were dissolved in distilled water to a final concentration of 7 and $2.45 \mathrm{mM}$ respectively. These two solutions were mixed and the mixture allowed to stand in the dark at room temperature for $16 \mathrm{~h}$ before use to produce ABTS radical (ABTS ${ }^{+}$). To examine the infusion samples, the ABTS. ${ }^{+}$solution was diluted with distilled water to an absorbance of 1.00 at $734 \mathrm{~nm}$. The extracts of the 10 brands in triplicate (final concentrations 
$0.0001-0.01 \mathrm{mg} / \mathrm{mL}$ ) or Trolox standards (final concentration 0-20 mM) were added to diluted ABTS. ${ }^{+}$solution, and the absorbance was read at $6 \mathrm{~min}$ after mixing using a spectrophotometer. The results are presented as the ability of the tea extract to scavenge free radical ABTS $\cdot{ }^{+}$(Trolox equivalent antioxidant capacity) (Re et al., 1999).

\subsubsection{Total aflatoxin: ELISA}

The level of aflatoxin B1 was measured by commercial aflatoxin B1 fast ELISA Kit (EuroProxima, Netherlands)according to a protocol for measuring aflatoxin B1 in food matrices. The method was performed by competitive enzyme technique based on antigen-antibody reaction. For ELISA analysis, $50 \mu \mathrm{L}$ of the samples or aflatoxin B1 standards (in duplicate) were added in each well, which was coated with specific antibodies against aflatoxin $\mathrm{B} 1$. After incubation in $37^{\circ} \mathrm{C}$ for $60 \mathrm{~min}$, the wells were washed three times and filled with rinsing buffer solution. Following additional incubation $\left(30 \mathrm{~min}\right.$ in dark at $\left.20^{\circ} \mathrm{C}\right), 100 \mu \mathrm{L}$ of substrate was added, and the reaction was stopped after $30 \mathrm{~min}$ of incubation in the dark at $25^{\circ} \mathrm{C}$. Sample absorption was measured in $450 \mathrm{~nm}$ by ELISA reader (SpectraMax M5, California - USA). The level of aflatoxin B1 in the samples is iverersely correlated with the sample absorption, calculated based on drawing a standard logarithmic curve.

\subsubsection{Statistical analysis}

The total phenolics content and antioxidant activity were compared applying analysis of variance (ANOVA) using the degree of significance of $95 \%(p<0.05)$. Additionally, to verify the internal control, each brand and control groups were compared to each other $(n=3)$ by using ANOVA.

For similarity analysis, the mass/charge $(\mathrm{m} / \mathrm{z})$ was the criterion for distinguishing for each molecule detected. A matrix of presence $(+)$ and absence (-) of chemical markers was constructed to prepare a cluster, the data in this matrix were subjected to the similarity analysis according to the Jaccard coefficient of similarity, which describes how similar the brands are in terms of shared chemical markers when compared with the control groups ((de Souza Mesquita et al., 2017). The same approach was used to analyze the presence $(+)$ and absence $(-)$ of histological characters of the sub-samples for histological control.

\section{Results}

\subsection{Macroscopic control}

Visual inspections of all 30 samples of $P$. major commercial herbs were analyzed to verify whether their production is uniform and in accordance with the regulations imposed by Brazilian National Health Surveillance Agency (ANVISA) (BRASIL, 2010). In all evaluated samples ( $n=30$, all 10 brands evaluated) inflorescences, stems, roots and racemes, as well as leaves contaminated with fungi, were observed. Moreover, small stone were observed in sample 1 of brand 3. In all samples of brand 8, soil sediment and coleopterans of the Bruchidae family were found. None of the samples evaluated in the present study was in compliance with ANVISA regulation.

\subsection{Histological analysis}

Table 1 was constructed from the observation of the histological sections from the 10 brands, containing the presence $(+)$ and absence $(-)$ of some key characteristics, which were applied as a basis for the clustering of anatomical similarity (Fig. 1). Brands 6, 7, 8 and 10 displayed characters with $100 \%$ of similarity to the authentic sample of $P$. major. Brands 3, 4 and 9 displayed 43\% similarity compared with the standard description of $P$. major, since its epidermal cells on both faces have irregular-shaped papillae and collateral type main vascular bundle, which are not characteristic of the species. All other evaluated brands presented $<30 \%$ similarity to the standard $P$. major, due to the presence of papillary epidermal cells (except for brand 5), collateral vascular main bundle, substomatic chambers and homogeneous mesophyll, which suggests cross contamination with other plant species.

Results concerning the anatomical features of the leaf fragments from the 10 different commercial brands of plantain teas are plated. In addition, a histological compilation of the 10 different leaf fragments from the commercial samples was generated (Figs. 2 and 3). The brands 1 (Fig. 2c), 3 (Fig. 2i), 4 (Fig. 2l) and 9 (Fig. 3k) displayed papillary epidermal cells on both leaf surfaces, different from those found in brands 2 (Fig. 2f), 5 (Fig. 2o), 6 (Fig. 3c), 7 (Fig. 3f), 8 (Fig. 3h) and 10 (Fig. 3n, o), resembling those of the authentic $P$. major, with rounded epidermal cells without papillae. All the brands evaluated, as well as the standard description of $P$. major, are amphistomatic, that is, they have stomata on both surfaces (Fig. 2c, f, i, 1 and o; Fig. 3c, f, h, k and o). A concave-convex central rib, characteristic of the genus Plantago, was observed in brands 3 (Fig. 2g), 6 (Fig. 3a), 7 (Fig. 3d), 8 (Fig. 3g), 9 (Fig. 3j) and 10 (Fig. 3m); the brands 1 (Fig. 2a), 2 (Fig. 2d), 4 (Fig. 2j), and 5 (Fig. $2 \mathrm{~m}$ ) had a planar-convex central rib. The main vascular bundle characteristic of $P$. major is bicolateral (phloem involves the xylem), as diagnosed for brands 4 (Fig. 2l), 6 (Fig. 3c), 7 (Fig. 3e), 8 (Fig. 3i), 9 (Fig. 31) and 10 (Fig. 30); the other brands had collateral main vascular bundle (Fig. $2 \mathrm{c}, \mathrm{h}$ and $\mathrm{n}$ ). The dorsiventral mesophyll, with the distinction of palisade and lacunate parenchyma was observed in the brands 3 (Fig. 2h), 6 (Fig. 3b), 7 (Fig. 3e), 8 (Fig. 3h) and 10 (Fig. 3n); the other brands had homogeneous mesophyll (Fig. 2b, e, k and n; Fig. 3k).

\subsection{Electrospray ionization mass spectrometry fingerprinting}

A total of 7 chemical markers were assessed, typical of the genus Plantago: aucubin ( $m / z 345)$, dershamnosylacteoside $(m / z ~ 477)$, acteoside $(\mathrm{m} / \mathrm{z} 623)$, methyl acteoside $(\mathrm{m} / \mathrm{z} 637)$, plantamajoside $(\mathrm{m} / \mathrm{z}$ 639), lavandulifolioside $(\mathrm{m} / \mathrm{z} 755)$ and plantamajoside-hexoside $(\mathrm{m} / \mathrm{z}$ 801) (de Souza Mesquita et al., 2017; Rønsted et al., 2000). These chemotaxonomic markers were analyzed by direct infusions coupled to a mass spectrometer (FIA-ESI-IT-MS ${ }^{\mathrm{n}}$ ). The presence $(+)$ and absence $(-)$ of these chemical markers were the basis for the construction of Table 2 and Fig. 4. The control groups were divided into two categories: (i) IC, inflorescence control and (ii) NIC, non-inflorescence control. Both categories contained all 7 markers evaluated. Therefore, the species do not show any variation of its markers in different stages of life (Fig. 4).

According to Table 2, showing the chemical markers, none of the evaluated brands presented aucubin. Brands 9 and 10 in all 3 samples presented 6 markers, all belonging to the class glycosylated phenylethanoids, suggesting that the authenticity of the samples analyzed as P. major ( $90 \%$ of chemical similarity). Brand 7 , in all 3 samples, showed the presence of 5 markers $(60 \%$ of chemical similarity with the control groups). Brand 3 presented a uniform chemical composition in all 3 samples, but a low chemical similarity compared to the control groups (only 40\%). However, brands 1, 2, 4, 5, 6 and 8 displayed 60\% similarity with the control groups, but with low uniformity in their production, since different markers in different samples were observed. Finally, sample 1 of brand 8 showed the lowest chemical similarity with the control groups $(\sim 20 \%)$, indicating a problem regarding the chemical composition of the active principles.

\subsection{Total phenolic content and antioxidant capacity}

The content of the phenolic compounds and the antioxidant capacity of the control groups are different from each other (Table 3). The infusion produced with the plants with the leaves in the reproductive stage (IC) presented more phenolic compounds $(11.1 \pm 0.2 \mathrm{mg} \mathrm{GAE} / \mathrm{g}$ tea) and a higher antioxidant capacity (878.9 $\pm 179.0 \mu \mathrm{mol}$ Trolox $/ \mathrm{g}$ tea) than the infusion produced from plants in the vegetative stage (NIC) $(10.7 \pm 0.2 \mathrm{mg} \mathrm{GAE} / \mathrm{g}$ tea, $659.0 \pm 92.7 \mu \mathrm{mol} \mathrm{Trolox} / \mathrm{g}$ tea $)$ (Table 3). 
Table 1

Presence (+) and absence (-) of some key anatomical characteristics. The characters used as authentically for $P$. major (control group) are based on de Souza Mesquita et al., 2017.

\begin{tabular}{|c|c|c|c|c|c|}
\hline Samples & Epidermical cells & Stomata + camera & Midrib & Vascular bundle from Midrib & Mesophyl \\
\hline Plantago major & + & + & + & + & + \\
\hline Brand 1 & - & + & - & - & - \\
\hline Brand 2 & + & + & - & - & - \\
\hline Brand 3 & - & + & + & - & + \\
\hline Brand 4 & - & + & - & + & - \\
\hline Brand 5 & - & + & - & - & - \\
\hline Brand 6 & + & + & + & + & + \\
\hline Brand 7 & + & + & + & + & + \\
\hline Brand 8 & + & + & + & + & + \\
\hline Brand 9 & - & + & + & + & - \\
\hline Brand 10 & + & + & + & + & + \\
\hline
\end{tabular}

(+) Characteristic equal to P. major; (-) Uneven characteristic to P. major.

The results expressed for the brands showed that there is no positive correlation between the quantification of phenolic compounds and the antioxidant activity, since the brand with the highest amount of phenolic compounds does not display the highest antioxidant activity. Only brand 3 reached a statistically similar value to the control group regarding the antioxidant activity $(308.9 \pm 206.6 \mu \mathrm{mol}$ Trolox/g tea), and only brand 9 showed a value equivalent to the control group in relation the quantification of phenolic compounds $(10.6 \pm 0.1 \mathrm{mg}$ $\mathrm{GAE} / \mathrm{g}$ tea). The other brands did not present statistically equivalent values when compared to the control groups, indicating low antioxidant activity (Table 3 ).

In addition, the brands were subjected to an internal quality control. Each sample from the same commercial brand was compared to two other samples of the same brand (Fig. 5). Brands 1, 4, 5, 7 and 8 have equivalent values in the three samples considering the amount of phenolic compounds and antioxidant capacity (Fig. 5). Brand 10 has in its three samples statistically equal antioxidant activity, despite a variation in the amount of the phenolic compounds, as sample 2 displayed a larger quantity when compared to samples 1 and 3. Brands 6 and 9 presented phenolic compound contents equivalents in the 3 samples; however, there was variation of antioxidant activity. Brands 2 and 3 showed great variations in the two parameters evaluated and most likely do not have uniformity in the harvesting and packaging process, consistent with the anatomical data, since both brands do not have anatomical description equivalent to authentic $P$. major leaves.

\subsection{Total aflatoxin content}

Aflatoxin was detected in all commercial samples (Table 3). It was not possible to quantify the total aflatoxin content of sample 1 of brand 6 and sample 3 of brand 8 , since there is more aflatoxin than the upper limit of quantification. All commercial brands are equivalent to each other of total aflatoxins (ANOVA: $\mathrm{F}=1.8412, p=0.1292$ ). No aflatoxins were detected in the authentic control groups (IC and NIC).

\section{Discussion}

The medicinal plants are effective and safe; thus, many people benefit from these natural products. However, there have been case reports of adverse reactions with the use of certain herbs. Many factors could contribute to these adverse reactions, such as poor quality control of commercial brands and toxicity. To ensure the necessary safety of tea, industries apply some quality control measures (Angelova et al., 2008). Nevertheless, due to insufficient and incorrect quality control analysis of the herbal teas, it is strongly recommended that the following minimum criteria for consumers safety be fulfilled: macroscopic

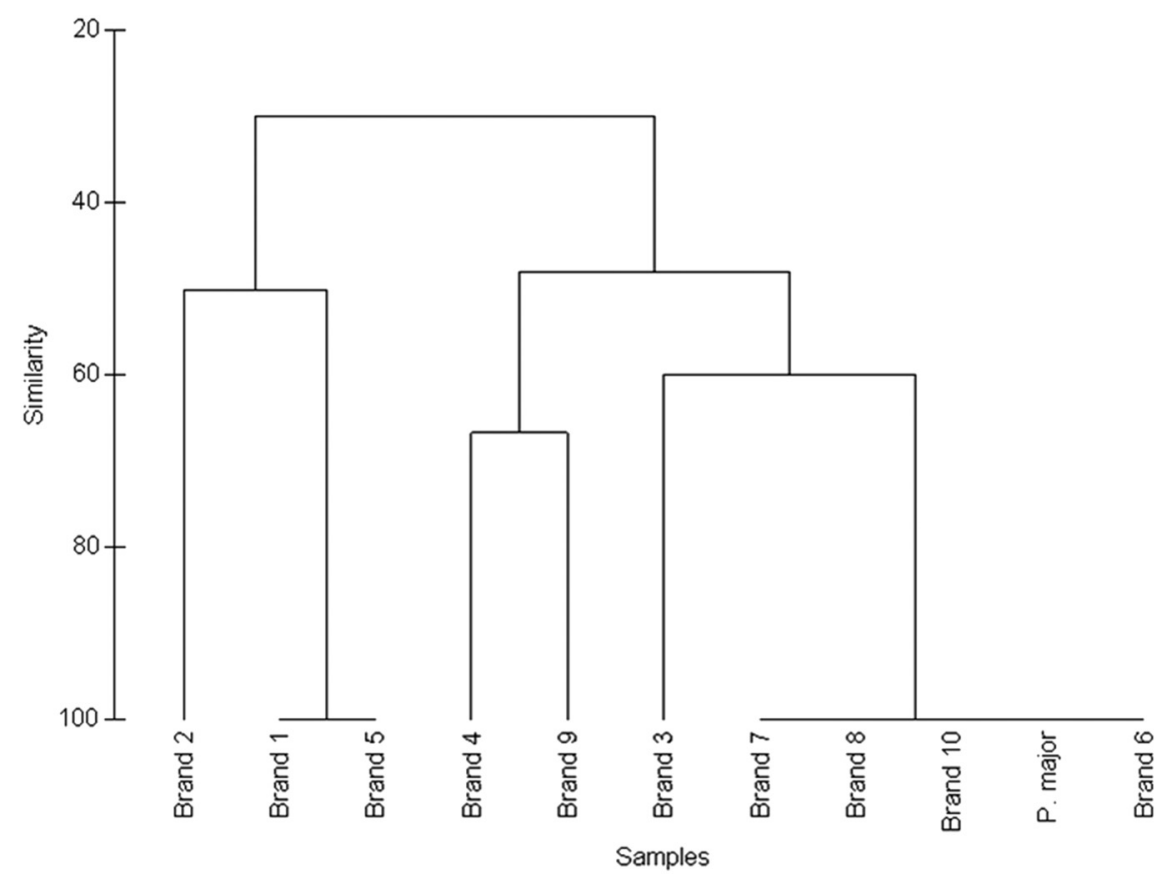

Fig. 1. Cluster of anatomical similarity of the leaf fragments of the commercial samples in comparison to the authentic leaf samples of $P$. major. 

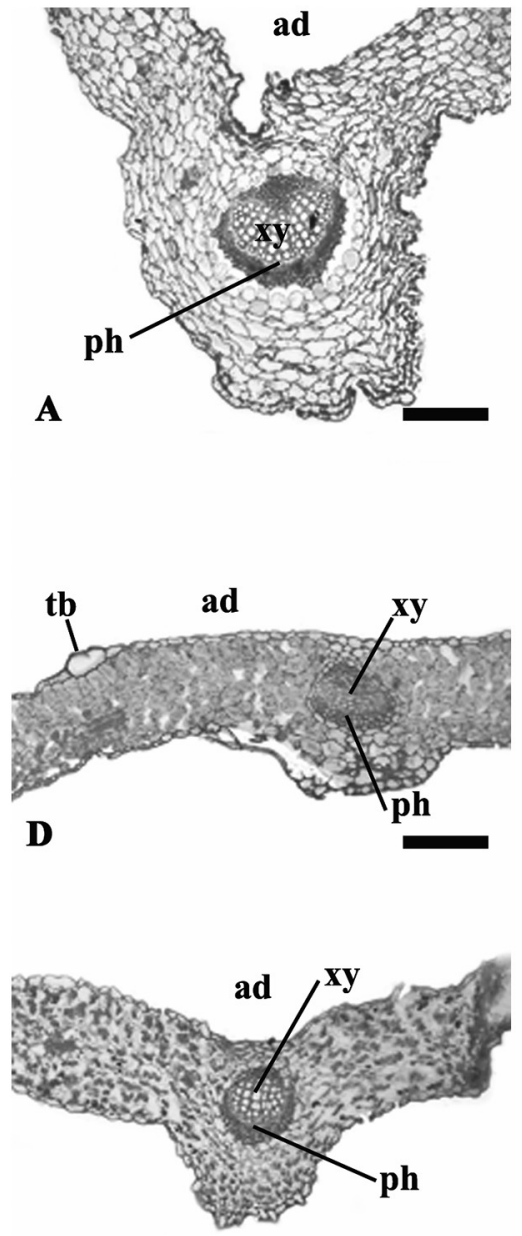

G
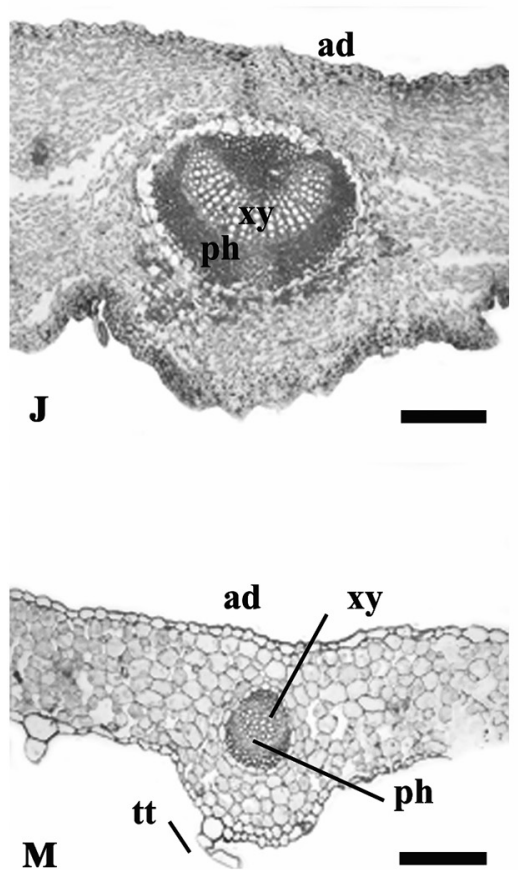

ad
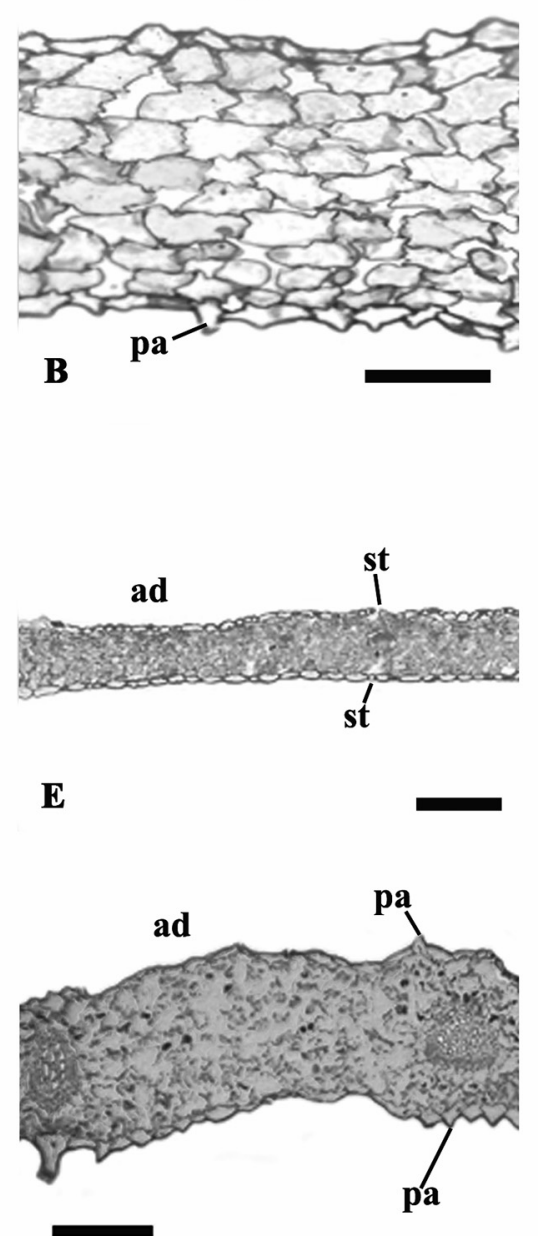

$\mathbf{H}$
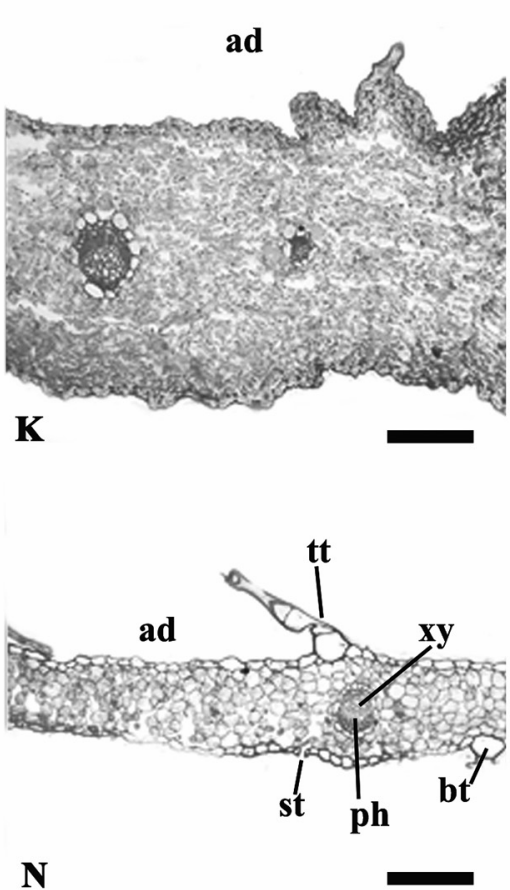
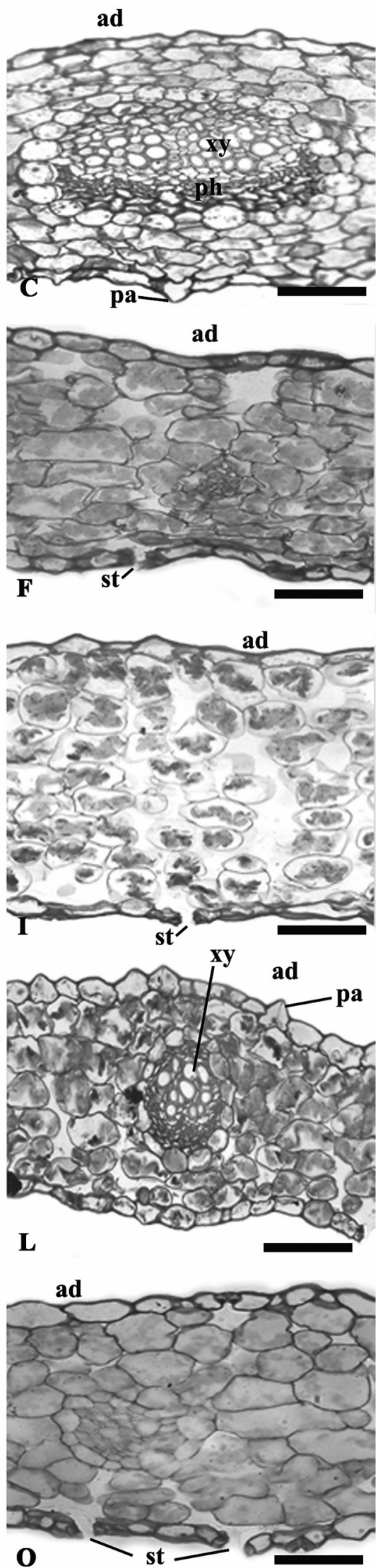

Fig. 2. Leaf anatomy of selected brands of commercial Plantain teas. A-C. Brand 1; D-F. Brand 2; G-I. Brand 3; J-L. Brand 4; N-O. Brand 5. A, D, G, J, M: midrib; B, E, H, K, N: mesophyll; C, F, I, L, O: detail of mesophyll. [ad: adaxial surface, bt: basal cell of trichome, pa: papila, st: stomata, tt: multicellular tector trichome.] Bars: $200 \mu \mathrm{m}$ (A, D, E, G, H, J, K, M, N), $50 \mu \mathrm{m}$ (B, C, F, I, L, o). 

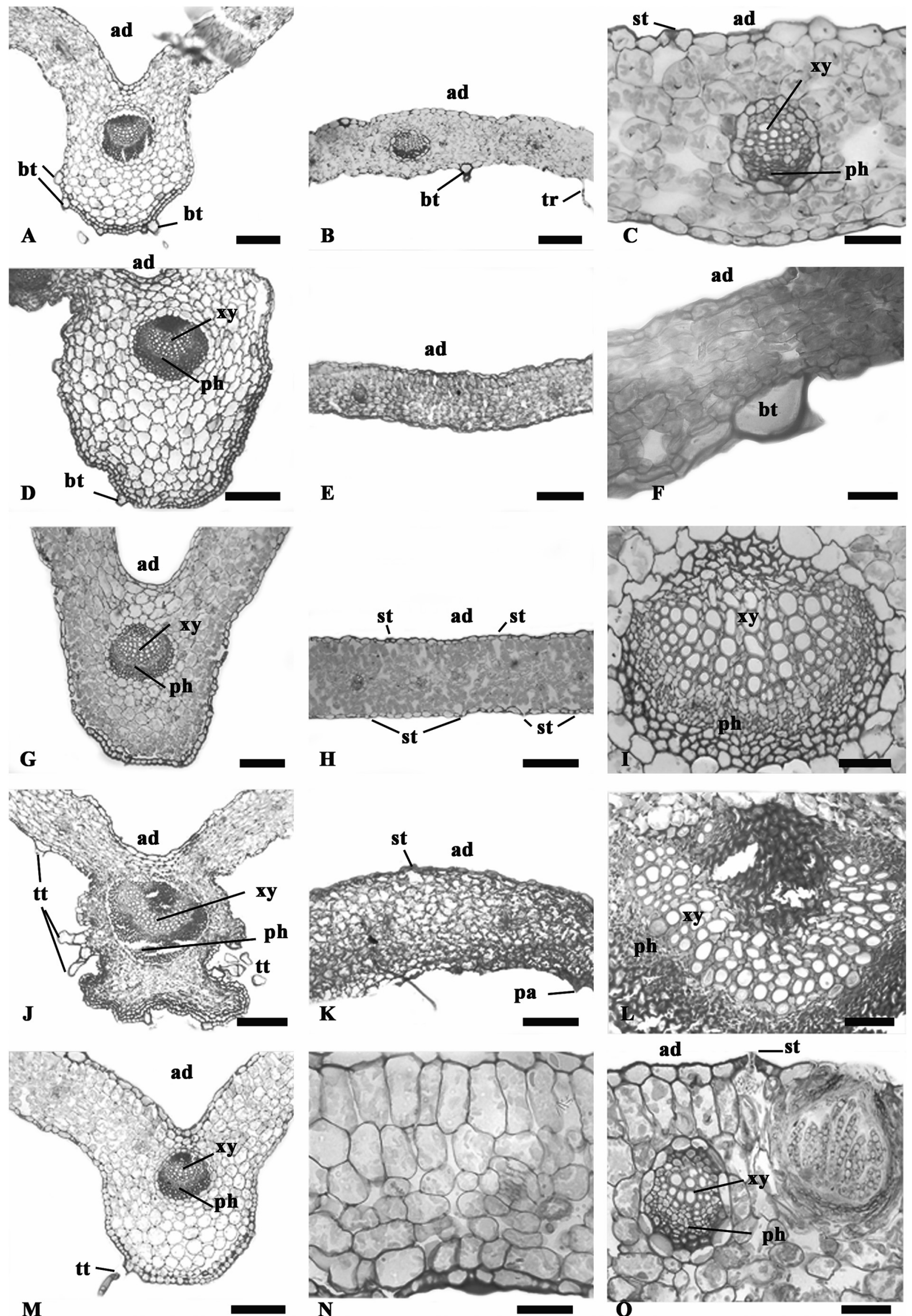

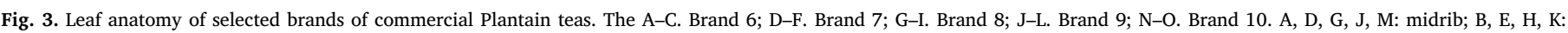

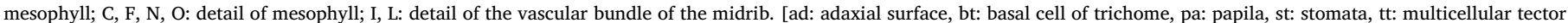
trichome.] Bars: $200 \mu \mathrm{m}$ (A, B, D, E, G, H, J, K, M), $50 \mu \mathrm{m}$ (C, F, I, L, N, O). 
control for identification of contaminant solid material; microscopic analyses for histological characterization; and chemical analysis of metabolic profile using Mass Spectrometry Fingerprinting. Other methods can be associated with those previously mentioned.

The present study was developed from the suspicion that teas marketed as Plantago major in Brazil were contaminated with other plant species (cross contamination), whether of the genus Plantago or others. However, the results of the present study are even more alarming. Leaves contaminated by fungi were found in all commercial samples, denoting a lack of care in the productive chain of the teas and in the sanitary control. The absence of the phenolic compounds observed in the mass spectrometry fingerprinting in relation to the found in the control groups alarmed us. We hypothesized that the presence of fungi could be the cause of the loss of these phenolic compounds. Therefore, we performed a quantification test of aflatoxins produced by fungi, since these compounds degrade phenolic compounds and producesecondary metabolites. Even in plants with key characteristics of $P$. major (brands 6, 7, 8 and 10) the antioxidant capacity and content of phenolic compounds was far below the expected results for this species.

The macroscopic control is used to characterize the sensorial attributes and to verify whether there is difference between them, to determine whether these products are acceptable for the consumer (Carpenter, Lyon, \& Hasdell, 1992). In the present study, with commercial herbal samples, the presence of inflorescences, stems, roots and racemes were found in all samples, suggesting that companies are not aware of Brazilian law regulations for $P$. major, which demonstrates an insufficient quality control on the part of the commercial companies of the teas. Stones, soil sediments and coleopterans of the Bruchidae family in the samples of commercial herbal teas evidence a lack of care in the harvest and/or storage by the manufacturer (Martins, Martins, Dias, \& Bernardo, 2001). Fungi in all samples evaluated might arise from an insufficient drying process or due to the gain of humidity during inappropriate storage, transportation or processing (Monbaliu, Wu, Zhang, Van Peteghem, \& De Saeger, 2010). The presence of these microorganisms in all samples of teas is worrisome, as degradation enzymes, such as oxygenase, hydroxylase, peroxidase and oxidase are able to decrease the phenolic content (Tebbouche, Hank, Zeboudj, Namane, \& Hellal, 2016). Additionally, the presence of these fungi may be an indicator of the presence of mycotoxins, such as aflatoxins, which are secondary metabolites, produced under stress conditions of the microorganism, during the drying and storage of the tea leaves, capable causing cancer and allergies (Magan \& Aldred, 2007; Zain, 2011). This type of contamination has already been reported in previous studies with herbal plants, due to the presence of the fungi (Pereira et al., 2017).

Many countries have legislation pertaining to the maximum content allowed for mycotoxins in foodstuffs, due to their health hazards for humans (Kabak \& Dobson, 2017). The European Union has the most extensive regulations for mycotoxins worldwide, and many countries, such as Brazil, use European legislation as a model for setting maximum levels for each type of food. The European Union has not yet established maximum levels of aflatoxins concentration in teas and herbal infusions. European regulatory sets in June 2015 that these commodities can be an important contributor to dietary exposure. However, in the absence of data on dry tea leaves and dry parts of other plants for the preparation of herbal infusions allowing the establishment of such a maximum level, occurrence data should be collected in view of the possible establishment of a specific maximum level in the future (Commission Regulation (EC) No. 2015/1005, 2015). Despite the absence of existing legislation for the control of aflatoxins in herbal infusions, the present results suggest that even in small amounts, the presence of aflatoxin may be detrimental to the content of phenolic compounds, which are responsible for the therapeutic benefit of Plantago infusions and other herbs. Herbal medicinal infusions, such as other herbs and spices represent a unique category of food. Due to their low water activity, microbial contamination may persist in these 


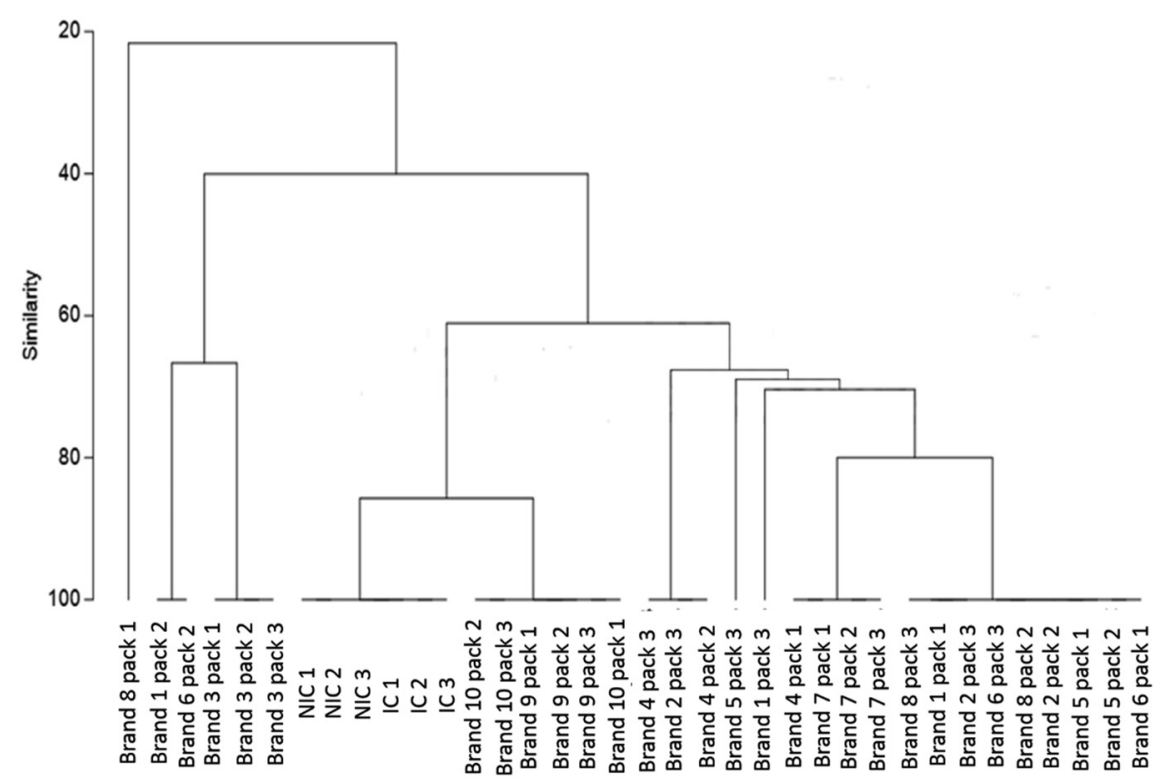

Fig. 4. Cluster of chemical similarity based on presence and absence of chemical markers.

foodstuffs, and assessment of their intake has become an important topic (Székács, Wilkinson, \& Appel, 2017).

Once the material has been examined and classified according to external characteristics, inspection by microscopy can be carried out as the next step for quality control. As previously mentioned, all brands showed unconformity regarding the macroscopic analysis. Similarly, we could detect some inconsistencies concerning the histological results. Notably, we evaluated only leaves fragments from a material that was already processed (dried and crushed). However, significant results were obtained after rehydration and reconstitution, enabling the

Table 3

Content of phenolic compounds, antioxidant activity and total aflatoxin content of the evaluated brands and control groups IC and NIC.

\begin{tabular}{|c|c|c|c|c|c|c|c|}
\hline Samples & Triplicate & $\begin{array}{l}\text { Total Phenolic Content } \\
\text { (mg GAE/g tea) } *\end{array}$ & $\begin{array}{l}\text { Mean + S.E.M } \\
(\mathrm{mg} \mathrm{GAE} / \mathrm{g} \text { tea) }\end{array}$ & $\begin{array}{l}\text { Antioxidant } \\
(\mu \mathrm{mol} \text { Trolox } / g)_{*}\end{array}$ & $\begin{array}{l}\text { Mean + S.E.M } \\
(\mu \mathrm{mol} \text { Trolox/g) }\end{array}$ & Aflatoxin Content $(\mu \mathrm{g} / \mathrm{kg})_{*}$ & $\begin{array}{l}\text { Mean + S.E.M } \\
(\mu \mathrm{g} / \mathrm{kg})\end{array}$ \\
\hline \multirow[t]{3}{*}{ IC } & Plant 1 & 11.0 & \multirow[t]{3}{*}{$11.1 \pm 0.2^{a}$} & 747.4 & \multirow[t]{3}{*}{$878.9 \pm 179.0^{a}$} & n.d. & \multirow[t]{3}{*}{ n.d. } \\
\hline & Plant 2 & 10.9 & & 806.5 & & n.d. & \\
\hline & Plant 3 & 11.3 & & 1082.8 & & n.d. & \\
\hline \multirow[t]{3}{*}{ NIC } & Plant 1 & 10.7 & \multirow[t]{3}{*}{$10.7 \pm 0.2^{b}$} & 693.5 & \multirow[t]{3}{*}{$659.0 \pm 92.7^{b}$} & n.d. & \multirow[t]{3}{*}{ n.d. } \\
\hline & Plant 2 & 10.6 & & 554.0 & & n.d. & \\
\hline & Plant 3 & 10.7 & & 729.4 & & n.d. & \\
\hline \multirow[t]{3}{*}{ Brand 1} & Sample 1 & 8.2 & \multirow[t]{3}{*}{$8.3 \pm 0.1^{f}$} & 319.4 & \multirow[t]{3}{*}{$302.4 \pm 23.1^{c}$} & 0.065 & \multirow[t]{3}{*}{$0.102 \pm 0.070^{a}$} \\
\hline & Sample 2 & 8.4 & & 276.1 & & 0.060 & \\
\hline & Sample 3 & 8.2 & & 311.7 & & 0.183 & \\
\hline \multirow[t]{3}{*}{ Brand 2} & Sample 1 & 2.1 & \multirow[t]{3}{*}{$2.3 \pm 0.2^{i}$} & 230.9 & \multirow[t]{3}{*}{$279.4 \pm 48.2^{c / d}$} & 0.078 & \multirow[t]{3}{*}{$0.069 \pm 0.018^{a}$} \\
\hline & Sample 2 & 2.3 & & 280.0 & & 0.080 & \\
\hline & Sample 3 & 2.4 & & 327.3 & & 0.048 & \\
\hline \multirow[t]{3}{*}{ Brand 3} & Sample 1 & 8.7 & \multirow[t]{3}{*}{$8.8 \pm 0.2^{e}$} & 546.9 & \multirow[t]{3}{*}{$308.9 \pm 206.6^{b}$} & 0.138 & \multirow[t]{3}{*}{$0.109 \pm 0.047^{a}$} \\
\hline & Sample 2 & 8.9 & & 203.4 & & 0.056 & \\
\hline & Sample 3 & 8.6 & & 176.4 & & 0.135 & \\
\hline \multirow[t]{3}{*}{ Brand 4} & Sample 1 & 5.7 & \multirow[t]{3}{*}{$5.6 \pm 0.3^{h}$} & 308.5 & \multirow[t]{3}{*}{$271.4 \pm 92.4^{c}$} & 0.061 & \multirow[t]{3}{*}{$0.053 \pm 0.009^{a}$} \\
\hline & Sample 2 & 5.3 & & 339.4 & & 0.044 & \\
\hline & Sample 3 & 5.8 & & 166.2 & & 0.054 & \\
\hline \multirow[t]{3}{*}{ Brand 5} & Sample 1 & 9.2 & \multirow[t]{3}{*}{$9.3 \pm 0.1^{d}$} & 149.1 & \multirow[t]{3}{*}{$138.2 \pm 10.6^{d}$} & 0.051 & $0.087 \pm 0.057^{a}$ \\
\hline & Sample 2 & 9.3 & & 137.6 & & 0.056 & \\
\hline & Sample 3 & 9.4 & & 128.0 & & 0.153 & \\
\hline Brand 6 & Sample 1 & 6.2 & $6.3 \pm 0.1^{g}$ & 152.4 & $241.0 \pm 84.2^{d}$ & $>$ & $0.082 \pm 0.008^{a}$ \\
\hline & Sample 2 & 6.4 & & 250.5 & & 0.088 & \\
\hline & Sample 3 & 6.4 & & 320.0 & & 0.076 & \\
\hline Brand 7 & Sample 1 & 10.2 & $10.2 \pm 0.1^{c}$ & 193.3 & $202.0 \pm 27.3^{d}$ & 0.037 & $0.038 \pm 0.022^{a}$ \\
\hline & Sample 2 & 10.1 & & 180.2 & & 0.060 & \\
\hline & Sample 3 & 10.2 & & 232.6 & & 0.016 & \\
\hline Brand 8 & Sample 1 & 2.6 & $2.5 \pm 0.2^{i}$ & 191.4 & $181.1 \pm 21.2^{d}$ & 0.051 & $0.048 \pm 0.004^{a}$ \\
\hline & Sample 2 & 2.5 & & 156.7 & & 0.045 & \\
\hline & Sample 3 & 2.3 & & 195.3 & & $>$ & \\
\hline Brand 9 & Sample 1 & 10.6 & $10.6 \pm 0.1^{b}$ & 176.1 & $177.5 \pm 1.8^{d}$ & 0.0186 & $0.022 \pm 0.019^{a}$ \\
\hline & Sample 2 & 10.7 & & 176.7 & & 0.006 & \\
\hline & Sample 3 & 10.6 & & 179.55 & & 0.042 & \\
\hline Brand 10 & Sample 1 & 10.2 & $10.3 \pm 0.1^{c}$ & 159.9 & $177.1 \pm 42.5^{d}$ & 0.047 & $0.049 \pm 0.015^{a}$ \\
\hline & Sample 2 & 10.4 & & 146.0 & & 0.038 & \\
\hline & Sample 3 & 10.2 & & 225.5 & & 0.065 & \\
\hline
\end{tabular}

${ }^{*}$ Equal letters in the same column represent statistically equivalent values; > : upper limit of quantification; n.d.: not detected. 

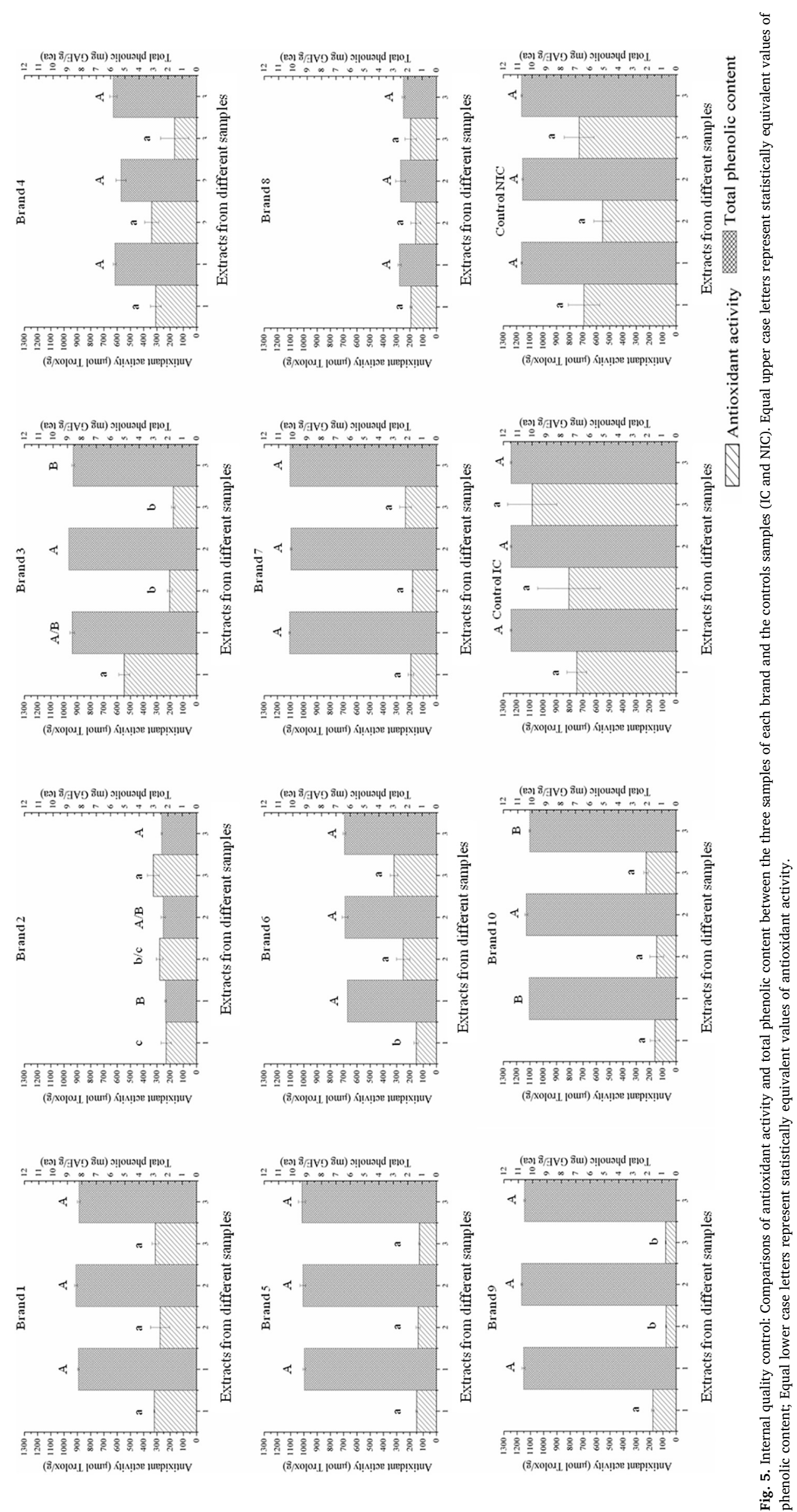
verification of several anatomic differences on the material analyzed when compared to the leaf anatomy of $P$. major used as a control, according to (de Souza Mesquita et al., 2017). The cluster of similarity analysis (Fig. 1) shows that four brands with similar characteristics to the control, and five of those with $<50 \%$, in fact, brand 1 showed only one character similar to the control, related to stomata in both surface of the leaf. Unfortunately, we were not able to identify the taxons that showed differences in the leaf anatomy. Accordind to (de Souza Mesquita et al., 2017), the correct identification of botanical material used for commercial herbal teas is very important. These authors demonstrated that close species from the same genus (Plantago) showed different chemical compounds, which cannot be used for the same pharmacological purpose. It seems that the companies are not concerned for the correct identification of the material produced since the harvesting stage, as they have collected plants other than $P$. major. In addition, there was also not care about the selection of the leaves, since were found every sort of plant organs along with leaves inside the samples.

In many cases, the histological analyses of the samples do not provide with data for the identification of the plant. Moreover, this technique cannot assure for the presence of the active principles of the phytomedicine. Therefore, it is important to complement the analyses with other analytical tools that can provide this information. The seven chemical markers of $P$. major were observed in IC and NIC. However, the markers in their totality were not detected in all samples. Aucubin ( $m / z 345$ ), a compound of $P$. major related to the anti-inflammatory activity, blood pressure reduction, liver protection, anti-microbial, analgesic and antitumor properties, was not detected in any studied sample (Xue et al., 2012). Environmental stress factors, such as drought, elevated temperature, salinity, and $\mathrm{CO}_{2}$, affect plant growth. Genes, proteins and metabolites change after individual and multiple environmental stresses. The responses to perturbations are typically accompanied by large changes in the transcriptome, proteome and metabolome of the plant (Ahuja, de Vos, Bones, \& Hall, 2010). Thus, these factors of environmental stress might have influenced the variation of the evaluated compounds, or these metabolites were degraded, since, even in brands with high histological similarity index with authentic $P$. major, we could not detect the same compounds.

Free radicals and reactive oxygen species (ROS) are residues of cellular metabolism, if not quickly eliminated, and these compounds can cause oxidative damage to functional molecules. Edible plants containing natural antioxidant compounds often possess strong antioxidant and free radical scavenging abilities, consequently provide health benefits and disease prevention (Li et al., 2015). Several studies have shown that medicinal plants are a rich source of antioxidant compounds, which may decrease the incidence of oxidative stress and associated diseases (Zhang et al., 2011). In relation to the control groups, the fact that the reproductive stage of $P$. major presents the highest level of phenolic compounds and the highest antioxidant activity (Table 3) suggests that, in this case, these factors may be related. (Queires \& Rodrigues, 1998) showed that in the reproductive phase of Schinus terebenthifolius there was an increase in total phenols, with the flowers reaching the highest value in comparison with the other organs. Thus, different cell types can regulate their own phenolic synthesis.

The literature regarding the phenolic profile and antioxidant activity of the $P$. major is scarce, therefore, it was not observed for many reference values, considering the consulted literature. (Beara et al., 2012) analyzed some Plantago species and found a total phenolic content of $42.62 \pm 1.04 \mathrm{mg} \mathrm{GAE} / \mathrm{g}$ of dry weight for $P$. major, a higher value than observed in the present study $(11.47 \pm 0.06 \mathrm{mg} \mathrm{GAE} / \mathrm{g}$ tea). However, in this case, the value was expressed in grams of tea, and not in dry weight. Although (Beara et al., 2012) also evaluated the antioxidant activity of the Plantago species, these authors did not apply the ABTS assay, but observed a reducing power of $73.89 \pm 4.42$ (mg of AAE/g of dry weight) by FRAP assay, for P. major.

Only one sample (Brand 9) presented a statistically similar phenolic value to that of the control group (NIC) (Table 3), however we did not find histological characteristics equivalent to Plantago major, that is, the consumer has no guarantee if the product in question is actually declared on the label. Additionally, phenolic compounds are one of the most representative classes in the genus Plantago related to its biological activity (Samuelsen, 2000) and since the level of phenolic compounds does not reach those of the herbal controls, their therapeutic efficacy can be questioned. Moreover, a large variation was observed in the phenolic content and of the antioxidant activity among different samples of the same brand. Together with the results obtained for the anatomical and microscopical analyses, we propose that contamination with other plants in the commercial samples is extremely likely.

The results obtained in the present study suggest that all the production processes of the teas marketed as $P$. major are compromised, considering the evaluated brands, since none of these samples presented satisfactory results in the tests of the present study. Although brands 6, 7, 8 and 10 have $100 \%$ anatomical similarity with $P$. major, they do not show equivalent total phenolic content, not even the total chemical markers. We hypothesized that the phenolic compounds are being degraded by the presence of fungi in the leaves and/or by the time the plants were harvested, including their age and the environmental conditions, as these factors may alter the total phenolic content. Furthermore, the season in which the harvest occurred and the environmental stressors can alter metabolites, which may have impaired the presence of characteristic markers of $P$. major. Therefore, it is essential that health surveillance agencies monitor the productive process of teas to ensure that their content complies with the regulations and that the species traded are correct. Only at that point are consumers assured that they are enjoying the true benefits of this type of drink. Therefore, all brands evaluated in the present study are not safe and do not have the medicinal benefits of $P$. major.

\section{Conclusions}

None of the commercial brands is adequate for consumption, since leaves with fungi and inadequate parts were observed in all samples; in one of the brands, sediments, stones and bugs were found. Only four brands have microscopic description compatible with authentic $P$. major leaves, which suggests that there is cross-contamination of other plant species. The therapeutic benefit of these teas comes from the high levels of phenolic compounds observed in the genus Plantago, which displays maked antioxidant activity. However, only two brands had equivalent levels in the phenolic compounds and antioxidant activity. Fingerprinting mass spectrometry assays are sensitive and applicable methods to verify which compounds are present in the samples. Unfortunately, these results are even more alarming, as all the chemical markers from Plantago major authentic samples were detected in none of the samples. Different chemical compounds cannot be used for the same pharmacological purpose. There is no way to know which plant is being marketed and whether this sample poses a potential health risk to the consumer. The difference of the present study is the integrative application of methods for success in the accurate quality control of $P$. major herbal teas, which can be applied to other species worldwide. In all the three dimensions of quality control analyzed in the present research, there were several contradictory results. One of the brands has the worst results on the macroscopic and chemical control; however, it this brand showed $100 \%$ similarity in the histological analysis, highlighting a need for an integrative quality control. Thus, our results stress the necessity for more rigorous inspections from the authorities, as even in the brands that histologically shoed leaf fragments with $P$. major characteristics did not have the expected antioxidant compounds. Thus, what are we imbibing when we drink a single $P$. major tea?

\section{Acknowledgements}

This work was supported by "Fundação de Amparo a Pesquisa do 
Estado de São Paulo-FAPESP" for fundings (2009/52237-9) and fellowships (2016/04394-1, 2011/23113-0).

\section{References}

Ahuja, I., de Vos, R. C., Bones, A. M., \& Hall, R. D. (2010). Plant molecular stress responses face climate change. Trends in Plant Science, 15(12), 664-674.

Angelova, N., Kong, H., Van Der Heijden, R., Yang, S., Choi, Y. H., Kim, H. K., ... Xu, G. (2008). Recent methodology in the phytochemical analysis of ginseng. Phytochemical Analysis, 19(1), 2-16.

Beara, I. N., Lesjak, M. M., Orčić, D. Z., Simin, N.Đ., Četojević-Simin, D. D., Božin, B. N., \& Mimica-Dukić, N. M. (2012). Comparative analysis of phenolic profile, antioxidant, anti-inflammatory and cytotoxic activity of two closely-related Plantain species: Plantago altissima L. and Plantago lanceolata L. LWT - Food Science and Technology, 47(1), 64-70. http://dx.doi.org/10.1016/j.lwt.2012.01.001.

BRASIL (2010). Resolução de Diretoria Colegiada (RDC) no 10, de 10 de março de 2010. Dispõe sobre a notificação de drogas vegetais.

Carpenter, R. P., Lyon, D. H., \& Hasdell, T. A. (1992). Guidelines for sensory analysis in food product development and quality control (1st ed.). . Retrieved from http://www. bookmetrix.com/detail/book/8b5a9de7-47b8-4ab7-a59a-66e6f6e58bfd\#citations.

Commission Regulation (EC) No. 2015/1005 (2015). Amending Regulation (EC) No 1881/ 2006 as regards maximum levels of lead in certain foodstuffs.

Govindaraghavan, S., \& Sucher, N. J. (2015). Quality assessment of medicinal herbs and their extracts: Criteria and prerequisites for consistent safety and efficacy of herbal medicines. Epilepsy \& Behaviour, 52(part B), 363-371. http://dx.doi.org/10.1016/j. yebeh.2015.03.004.

Janković, T., Zdunić, G., Beara, I., Balog, K., Pljevljakušić, D., Stešević, D., \& Šavikin, K. (2012). Comparative study of some polyphenols in Plantago species. Biochemical Systematics and Ecology, 42, 69-74. http://dx.doi.org/10.1016/j.bse.2012.02.013.

Jensen, W. A. W. A. (1962). Botanical histochemistry: Principles and practice.

Ji, H.-F., Li, X.-J., \& Zhang, H.-Y. (2009). Natural products and drug discovery. Can thousands of years of ancient medical knowledge lead us to new and powerful drug combinations in the fight against cancer and dementia? EMBO Reports, 10(3), 194-200. http://dx.doi.org/10.1038/embor.2009.12.

Kabak, B., \& Dobson, A. D. (2017). Mycotoxins in spices and herbs-An update. Critical Reviews in Food Science and Nutrition, 57(1), 18-34.

Li, S., Tan, H.-Y., Wang, N., Zhang, Z.-J., Lao, L., Wong, C.-W., \& Feng, Y. (2015). The role of oxidative stress and antioxidants in liver diseases. International Journal of Molecular Sciences, 16(11), 26087-26124.

Magan, N., \& Aldred, D. (2007). Post-harvest control strategies: Minimizing mycotoxins in the food chain. Mycotoxins from the Field to the Table, 119(1), 131-139. http://dx.doi. org/10.1016/j.ijfoodmicro.2007.07.034.

Martins, H. M., Martins, M. L., Dias, M. I., \& Bernardo, F. (2001). Evaluation of microbiological quality of medicinal plants used in natural infusions. International Journal of Food Microbiology, 68(1), 149-153. http://dx.doi.org/10.1016/S0168-1605(01) 00480-9.

Monbaliu, S., Wu, A., Zhang, D., Van Peteghem, C., \& De Saeger, S. (2010). Multimycotoxin UPLC - MS /MS for tea, herbal infusions and the derived drinkable products. Journal of Agricultural and Food Chemistry, 58(24), 12664-12671.

Oh, J., Jo, H., Cho, A. R., Kim, S.-J., \& Han, J. (2013). Antioxidant and antimicrobial activities of various leafy herbal teas. Food Control, 31(2), 403-409. http://dx.doi. org/10.1016/j.foodcont.2012.10.021.

Pandey, R., Shukla, S., Saraf, S., \& Saraf, S. (2013). Standardization and validated high- performance thin-layer chromatographic fingerprint method for quantitative determination of plumbagin in a traditional Indian formulation. JPC-Journal of Planar Chromatography-Modern TLC, 26(5), 440-444.

Pereira, E., Barros, L., Antonio, A. L., Cabo Verde, S., Santos-Buelga, C., Ferreira, I. C., \& Rodrigues, P. (2017). Is gamma radiation suitable to preserve phenolic compounds and to decontaminate mycotoxins in aromatic plants? A case-study with Aloysia citrodora Paláu. Molecules, 22(3), 347.

Poethig, R. S. (2013). Vegetative phase change and shoot maturation in plants. Current Topics in Developmental Biology, 105, 125-152. http://dx.doi.org/10.1016/B978-012-396968-2.00005-1.

Qi, M., Xiong, A., Geng, F., Li, Y., \& Wang, Z. (2012). A novel strategy for target profiling analysis of bioactive phenylethanoid glycosides in Plantago medicinal plants using ultra-performance liquid chromatography coupled with tandem quadrupole mass spectrometry. Journal of Separation Science, 35(12), 1470-1478. http://dx.doi.org/ 10.1002/jssc. 201200010.

Queires, L. C. S., \& Rodrigues, L. E. A. (1998). Quantificação das substâncias fenólicas totais em órgãos da aroeira Schinus Terebenthifolius (RADDI). Brazilian Archives of Biology and Technology, 41(2) (0-0).

Re, R., Pellegrini, N., Proteggente, A., Pannala, A., Yang, M., \& Rice-Evans, C. (1999). Antioxidant activity applying an improved ABTS radical cation decolorization assay. Free Radical Biology and Medicine, 26(9), 1231-1237. http://dx.doi.org/10.1016/ S0891-5849(98)00315-3.

Rønsted, N., Göbel, E., Franzyk, H., Jensen, S. R., \& Olsen, C. E. (2000). Chemotaxonomy of Plantago. Iridoid glucosides and caffeoyl phenylethanoid glycosides. Phytochemistry, 55(4), 337-348. http://dx.doi.org/10.1016/S0031-9422(00) 00306-X.

Samuelsen, A. B. (2000). The traditional uses, chemical constituents and biological ac tivities of Plantago major L. A review. Journal of Ethnopharmacology, 71, 1), 1-21. http://dx.doi.org/10.1016/S0378-8741(00)00212-9.

Singleton, V. L., \& Rossi, J. A. (1965). Colorimetry of total phenolics with phosphomolybdic-phosphotungstic acid reagents. American Journal of Enology and Viticulture, 16(3), 144.

Smith, F. H., \& Smith, E. C. (1942). Anatomy of the inferior ovary of Darbya. American Journal of Botany, 29(6), 464-471. http://dx.doi.org/10.2307/2437312.

de Souza Mesquita, L. M., Colpo, K. D., da Rocha, C. Q., Gatte-Picchi, D., Tangerina, M. M. P., Zachello-Nunes, B., ... Vilegas, W. (2017). Anatomical differentiation and metabolomic profiling: A tool in the diagnostic characterization of some medicinal Plantago species. Brazilian Journal of Botany, 40(3), 801-810.

Székács, A., Wilkinson, M. G., \& Appel, B. (2017). Environmental and food safety of spices and herbs along global food chains.

Tebbouche, L., Hank, D., Zeboudj, S., Namane, A., \& Hellal, A. (2016). Evaluation of the phenol biodegradation by Aspergillus niger: Application of full factorial design methodology. Desalination and Water Treatment, 57(13), 6124-6130.

World Health Organization (2014). WHO traditional medicine strategy 2014-2023. Geneva 2013.

Xue, H. Y., Lu, Y. N., Fang, X. M., Xu, Y. P., Gao, G. Z., \& Jin, L. J. (2012). Neuroprotective properties of aucubin in diabetic rats and diabetic encephalopathy rats. Molecular Biology Reports, 39(10), 9311-9318.

Zain, M. E. (2011). Impact of mycotoxins on humans and animals. Journal of Saudi Chemical Society, 15(2), 129-144. http://dx.doi.org/10.1016/j.jscs.2010.06.006.

Zhang, L., Ravipati, A. S., Koyyalamudi, S. R., Jeong, S. C., Reddy, N., Smith, P. T., ... Wu, M. J. (2011). Antioxidant and anti-inflammatory activities of selected medicinal plants containing phenolic and flavonoid compounds. Journal of Agricultural and Food Chemistry, 59(23), 12361-12367. 